\title{
Original Article (short paper) \\ Motor learning in post stroke subjects: the effects of practice conditions on the temporal synchronization
}

\author{
Camila Torriani-Pasin ${ }^{1}$, Giordano Marcio Gatinho Bonuzzi ${ }^{1 *}$, Gisele Carla dos Santos Palma ${ }^{1}$, Andrea Michele Freu- \\ denheim ${ }^{1}$, Umberto Cesar Corrêa $^{1}$ \\ ${ }^{1}$ Universidade de São Paulo, USP, Escola de Educação Física e Esporte, São Paulo, SP, Brazil
}

\begin{abstract}
Aims: The aim of this study was to investigate the effects of practice schedule on the motor learning of a synchronization timing task in post-stroke subjects. Subjects and Methods: Seventeen post-stroke individuals were assigned to the experimental group and for the control group were selected seventeen healthy individuals. At the acquisition phase, all participants performed 30 trials of a coincident timing task. Nine individuals from each group practiced constantly and eight from each group practiced randomly, with speed changes in the task. Subsequent phases included: 1) immediate transfer test and 2) long term transfer test after 3 days. Data were analyzed in relation to absolute, variable, and constant errors to assess the performance concerning accuracy, consistence, and direction of responses, respectively. Results: All groups increased their accuracy through the practice and were able to adapt it in different speeds. The stroke subjects were more variable in their motor responses. There was no effect of the practice schedule on motor learning, regardless the presence or absence of the neurologic damage. Conclusion: Post stroke individuals were able to learn a synchronizing task and the capacity of adapt their performance after speed perturbation was preserved. There was no effect of the practice schedule on motor learning.
\end{abstract}

Keywords: stroke; coincidence timing; practice condition; contextual Interference.

\section{Introduction}

Practice is essential to learning and through the improvement in practice is characterized the skillful behavior ${ }^{1}$, the manipulation of this factor affect the abilities acquisition. Stroke subjects, through the optimal practice are able to recover physical and cognitive function, improving functional skills ${ }^{2}$.

Practice generally occur through of three forms concerning its degree of variation: constant, blocked, and random. In the constant practice the task is unchanged throughout the acquisition phase. Moderate variability is provided for the blocked practice. And, the random is that varied practice in which the task is modified randomly providing a high degree of variability ${ }^{3}$.

Studies on practice scheduling in motor learning area have been developed based on the assumption that random practice facilitates the transfer and retention of motor skills by adding parameters (e.g. schema enrichment ${ }^{4}$ ) or strengthening of representations (e.g action plan ${ }^{5}$ ) of practiced skills in the memory. For instance, one could say that the diversification of parameter by variability of practice would allow the learner to more effectively relate response specifications and sensorial consequences of the movement needed to meet the demands of a new task ${ }^{4}$.

Behavioral and neurophysiological analyses has verified that random practice facilitates consolidation of motor memory $^{6}$,creating a more flexible and adaptable consolidation ${ }^{7}$. In fact, it is related that random conditions engages specific neural substrate during motor learning process which are related to transfer condition of the skill practiced ${ }^{8}$. Therefore, long term transfer tests are indicated to assess the random effect on motor learning processes ${ }^{1}$, being the adaptability, assessed by this test, an important issue for neurorehabilitation sessions? .

After a unilateral stroke, the neural areas related to motor learning can be affected ${ }^{10}$, in special those areas responsible for implicit learning demands ${ }^{11}$. Considering the peculiarity of the areas that can be affected, and given that sensorial ${ }^{12}$, motor $^{13}$, and cognitive ${ }^{14}$ and memory impairment ${ }^{15}$ contribute to the functional disability in $75 \%$ of post-stroke survivors ${ }^{10}$. It becomes crucial consider the acquisition of motor skills ${ }^{10,16}$.

A few studies have investigated the process of skill acquisition in subjects with neurological lesions ${ }^{17,18}$ and concluded that, in functional motor tasks, practice schedule may influence the functional performance and learning of hemiparetic subjects. Recent studies have been done in order to investigate motor performance after a stroke; however the investigation about motor learning process and the effects of practice on this process is still needed ${ }^{11,19,20}$.

In sum, because of divergence in the results, it remains unclear whether the effects of practice schedule were a consequence of the learning process, and/or of aspects that are related to the effector control of the hemiparetic limb. Thus, to distinguish the effect of practice schedule on motor learning decreasing the effects from motor control deficits on this process, we carried out an experiment in which stroke patients used the ipsilateral arm to lesioned hemisphere to perform a coincident timing task.

The temporal synchronization demand during the performance of timing coincidence task is a highly associated with the performance of several Activities of Daily Life (ADL's) and motor skills ${ }^{21}$. By improving temporal synchronization in stroke patients, we may allow improvement on motor performance skills that may reflect on the ADL. Therefore, the aim of this study was to investigate the effects of practice schedule on motor learning of a synchronization timing task in post-stroke patients. We hypothesized that post-stroke subjects would beneficiate by random conditions of practice even though both structures of practice (random and blocked) may induce motor learning. Besides, stroke subjects would have motor performance impaired 
by psychomotor deficits when compared to neurological health control subjects.

\section{Materials and Methods}

This study was approved by the University Ethics Committee from School of Physical Education and Sport - University of São Paulo and it was registered at Clinical Trials.gov (Id NCT00604747). All the participants signed the term of consent.

\section{Subjects}

The experimental group (EG) was composed by 16 hemiparetic subjects, male and female, from 40 to 60 years old. For the EG, the eligibility criteria were: first stroke; lesion covering the middle and the anterior cerebral artery territories; sufficient attention and comprehension to perform the task; absence of other associated neurological diseases. The EG was randomly assigned considering lesioned hemisphere into two groups: Random Experimental Group (REG) and Constant Experimental Group (CEG), which practiced the task in a random condition and constant condition, respectively.

The control group (CG) was comprised by 16 healthy subjects, male and female, from 40 to 60 years old. Control participants were matched by age to the experimental group and were also assigned in two groups regarding to condition practice offered: Random Control Group (RCG) and Constant Control Group (CCG).

For characterization of the experimental group the following evaluation measures and tests were used: Orpington Prognostic Scale, The Fugl-Meyer (FM) Assessment and Mini Mental State Evaluation (MMSE). We also included information about age, gender, hemisphere injured, and time of injury.

\section{Instruments and Tasks}

The task is a coincident timing task with synchronization demand. It requires that the participants press the response button coincident to stimuli in motion (lighting of the last diode). This type of task has been used in a few studies of motor control and learning and with different populations ${ }^{22,23}$. This task was chosen due its potential of learning for this population, and methodological feasibility. This coincident timing task required the prediction of a future position of the stimulus and the organization of a motor response to perform it coincident to the stimulus' arrival at the predicted place (Poulton, 1957).

The equipment of the coincidence timing task (Lafayette Instrument Co., Model 50575) is composed of a control screen, one $1.52 \mathrm{~m}$ gutter with 32 diodes placed on it linearly, and a response button. The screen has a digital display, with commands that permit the operator to control the stimulus propagation speed and the preparatory interval time. Once activated, the screen exhibits an alert signal, and, after the preparatory time interval, it initiates the propagation of a sequence of 32 luminous stimulus lighting. Thus, the goal task is to press the response button as coincidence as possible at the moment that the last diode to be light. More information about the equipment and the task can be found in previous works of our group ${ }^{25-27}$.

\section{Design and procedures}

Participants sat on a chair in front of a gutter, with its distal part raised from the floor and inclined so that they could clearly see all the diodes. Each participant received verbal instructions about the task in advance, and then performed two practice trials to become familiar with it.

When an alert signal was given, the participant was instructed in to be alert and to press the response button according with the luminous stimuli. Control participants used dominant member to perform the task, and stroke subjects performed the task with the less affected arm. The task performance was conducted with the less affected arm in order to distingue the motor impairments deficits from the motor learning impairments. This methodological design was conducted in previous studies (i.e. ${ }^{10,16,28}$ ).

In the acquisition phase, the constant practice groups (CEG and $C C G$ ) performed 30 trials on task at a stimulus propagation speed of 3 miles per hour (mph); the random practice groups (REG and RCG) performed 30 trials at speeds of $2 \mathrm{mph}, 3$ $\mathrm{mph}$, and $5 \mathrm{mph}$.

To assess the adaptability of the improved performance derived from the practice, we used two transfer tests in two moments after the blocks of practice. This transfer tests were conducted in two different speeds, one of them at $4 \mathrm{mph}$ (V4) which is closer to those of $3 \mathrm{mph}$ practiced during acquisition phase by all participants; and other at $1 \mathrm{mph}$ (V1) was comparatively longer than speeds practiced during acquisition phase ${ }^{29}$. During transfer tests, each subject performed 5 trials on these two conditions of speed in a counterbalanced order.

Thus, the design involved two transfer tests: an immediate transfer (TR1) which was performed after of the acquisition phase, and a long-term transfer test that was performed after 3 days of the acquisition phase (TR2).

During the acquisition phase was given for the participants the feedback in a results knowledge fashion, specifically was said: "You are right" or "You are wrong." Responses made in advance up to 10 milliseconds (msec) of the actual lighting of the last diode were considered "right." During the transfer test, no feedback was provided.

\section{Statistical analysis}

Data were analyzed in blocks of five trials considering the first (pre-test) and the last acquisition blocks (post-test), immediate transfer (TR1-V1 and TR1-V4), and long-term transfer (TR2-V1 and TR2-V4). The data were analyzed in relation to absolute, variable, and constant. These errors are well defined and very used in motor learning (Schmidt, Lee ${ }^{21}$ ); specially in space-temporal analyses, because they can assess different aspects of the performance concerning the accuracy and magnitude of 
the error (absolute error), consistence and variability (variable error), and direction of responses, that is, anticipation or delay (constant error).

To consider the interactions between groups (CEG, REG, CCG and RCG) and blocks of trials for each error, a 4 x 4 mixedmodel ANOVAs were conducted with repeated measures on the last factor (pre-test, post-test, TR1-V1, TR2-V1) and (pre-test, post-test, TR1-V4, TR2-V4) for each transfer test separately, with Tukey-HSD tests for analyses post-hoc. For all analyses, the level of significance was set at alfa $<.05$. All inferential analyses was run in STATISTICA ${ }^{\circledR} 12.0$ software (Stat Soft Inc., Tulsa, USA).

\section{Results}

In the Table 1 is showed the data of characterization of the CEG and REG.

Table 1: Characterization of the experimental group.

\begin{tabular}{cccccccccc}
\hline $\begin{array}{c}\text { Practice } \\
\text { Schedule }\end{array}$ & Gender & $\begin{array}{c}\text { Age } \\
\text { (years) }\end{array}$ & $\begin{array}{c}\text { Stroke } \\
\text { Side }\end{array}$ & Handedness & $\begin{array}{c}\text { Time from } \\
\text { stroke(months) }\end{array}$ & $\begin{array}{c}\text { Mini Mental } \\
\text { State Exam }\end{array}$ & $\begin{array}{c}\text { Orpington } \\
\text { Scale }\end{array}$ & $\begin{array}{c}\text { FM } \\
\text { (UE) }\end{array}$ & $\begin{array}{c}\text { FM } \\
\text { (LE) }\end{array}$ \\
\hline C & M & 57 & L & R & 28 & 27 & Mo & 43 & 23 \\
C & F & 59 & L & R & 53 & 30 & Mo & 28 & 24 \\
C & M & 60 & L & R & 10 & 25 & Mo & 46 & 28 \\
C & M & 49 & L & R & 33 & 24 & S & 15 & 8 \\
C & F & 57 & L & R & 12 & 28 & Mo & 44 & 30 \\
C & F & 58 & R & R & 48 & 28 & M i & 58 & 32 \\
C & M & 54 & R & R & 27 & 29 & Mo & 42 & 12 \\
C & F & 57 & R & R & 15 & 25 & Mo & 58 & 24 \\
Ran & M & 56 & R & R & 22 & 27 & Mo & 43 & 19 \\
Ran & M & 56 & R & R & 8 & 27 & Mo & 43 & 10 \\
Ran & F & 59 & R & R & 11 & 30 & Mi & 56 & 30 \\
Ran & F & 47 & L & R & 18 & 28 & Mo & 33 & 18 \\
Ran & M & 57 & L & R & 25 & 27 & Mo & 26 & 13 \\
Ran & F & 60 & R & R & 49 & 25 & S & 22 & 11 \\
Ran & M & 58 & L & R & 34 & 26 & Mo & 46 & 24 \\
Ran & F & 57 & L & R & 55 & 28 & Mo & 38 & 22 \\
\hline
\end{tabular}

Legend: $\mathrm{F}=$ Female; $\mathrm{M}$ = Male, $\mathrm{C}=$ constant; Ran = random; $\mathrm{R}=$ right; $\mathrm{L}=$ left; $\mathrm{Mi}=$ Mild; $\mathrm{Mo}=$ Moderate; $\mathrm{S}=$ Severe; FM = Fugl-Meyer Scale; $\mathrm{UE}=$ upper extremity; LE $=$ lower extremity.

Concerning the absolute error, the Anova two way test revealed effects only for moments, considering $\mathrm{V} 1$ transfer test $(\mathrm{F}(3,35)=7.42, \mathrm{p}=0.0001)$ and $\mathrm{V} 4$ transfer test $(\mathrm{F}(3$, $35)=6.87, p=0.0003)$. Post hoc testing showed that the pretest had greater absolute error than the post-test $(p=0.001)$, TR1-V1 $(p=0.01)$, TR1-V4 $(p=0.001)$, TR2-V1 $(p=0.0002)$, TR2-V4 ( $\mathrm{p}=0.003)$.

All groups demonstrated improvement of the accuracy through the practice, regardless the practice condition or neurologic condition, with no intergroup differences, as seen in Figure 1.

For constant error, there were statistical differences in the moments in both ANOVA analyses, with V1 transfer tests $(\mathrm{F}(3,35)=5.24, \mathrm{p}=0.002)$ and $\mathrm{V} 4$ transfer tests $(\mathrm{F}(3,35)=$ $4.69, \mathrm{p}=0.004)$. The post hoc test indicated the difference was mainly between pre-test and all moments, post-test $(p=0.009)$, TR1-V1 ( $=0.03)$, TR1-V4 $(p=0.01)$, TR2 - V1 $(p=0.003)$ e TR2-V4 ( $\mathrm{p}=0.004)$.

This way, the Anova two way results for constant error demonstrate that, in general, all participants iniciated the practice performing late motor responses, and along of practice, they were more synchronized or even antecipating the response, as demonstrated in Figure 2. 
Figure 1= Mean of the absolute error along blocks of trials for all groups. Legend: CEG - Constant Experimental Group, REG - Random Experimental Group, CCG - Constant Control Group, RCG - Random Control Group, TR1 - Immediate Transfer Test, TR2 - Long Term Transfer Test, V1 - Speed at $1 \mathrm{mph}, \mathrm{V} 4$ - Speed at $4 \mathrm{mph}, *$ - Significant difference in relation to pre-test for all groups.

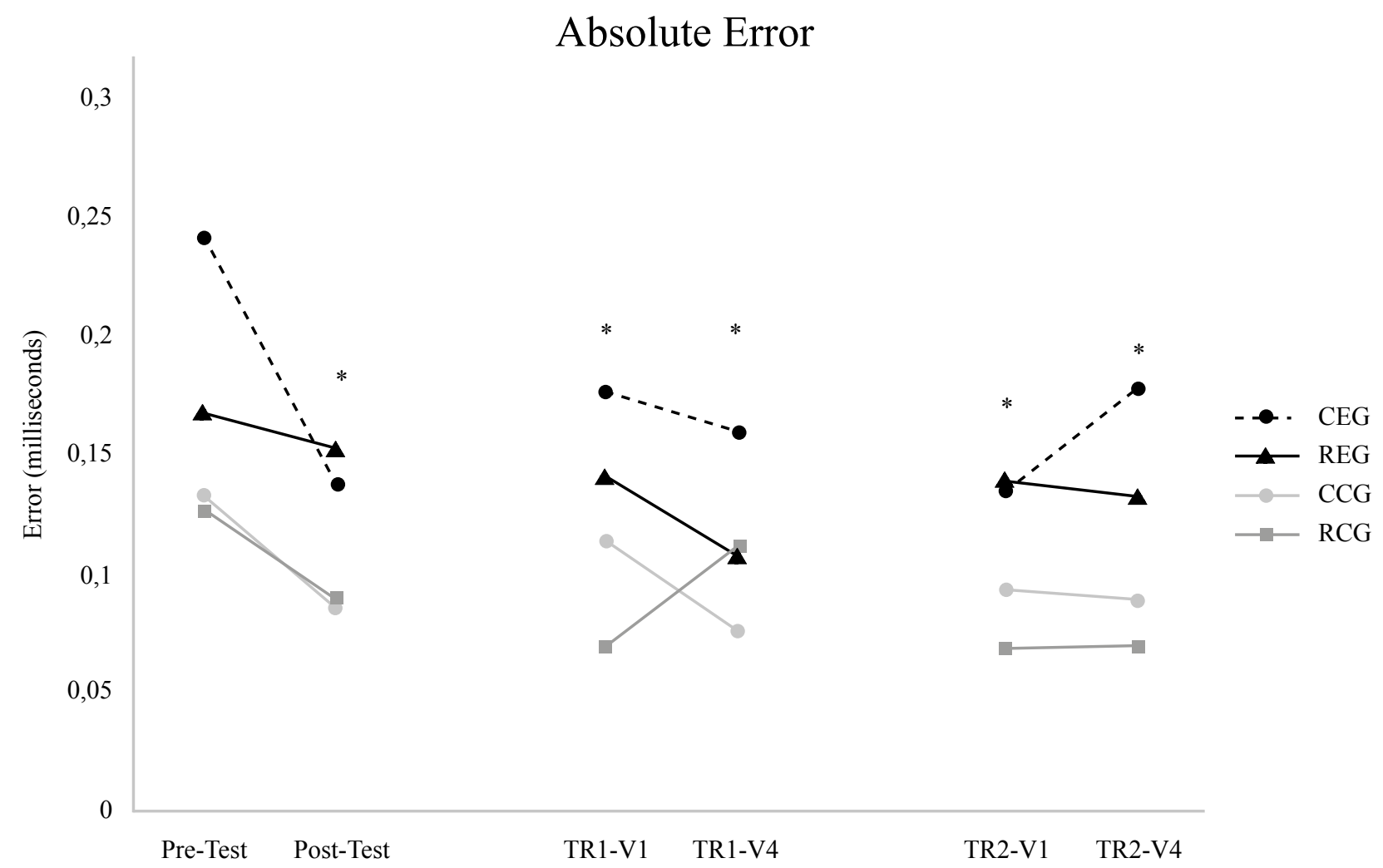

Figure 2= Mean of the constant error along blocks of trials for all groups. Legend: CEG - Constant Experimental Group, REG - Random Experimental Group, CCG - Constant Control Group, RCG - Random Control Group, TR1 - Immediate Transfer Test, TR2 - Long Term Transfer Test, V1 - Speed at $1 \mathrm{mph}, \mathrm{V} 4$ - Speed at $4 \mathrm{mph}, *$ - Significant difference in relation to pre-test for all groups.

Constant Error

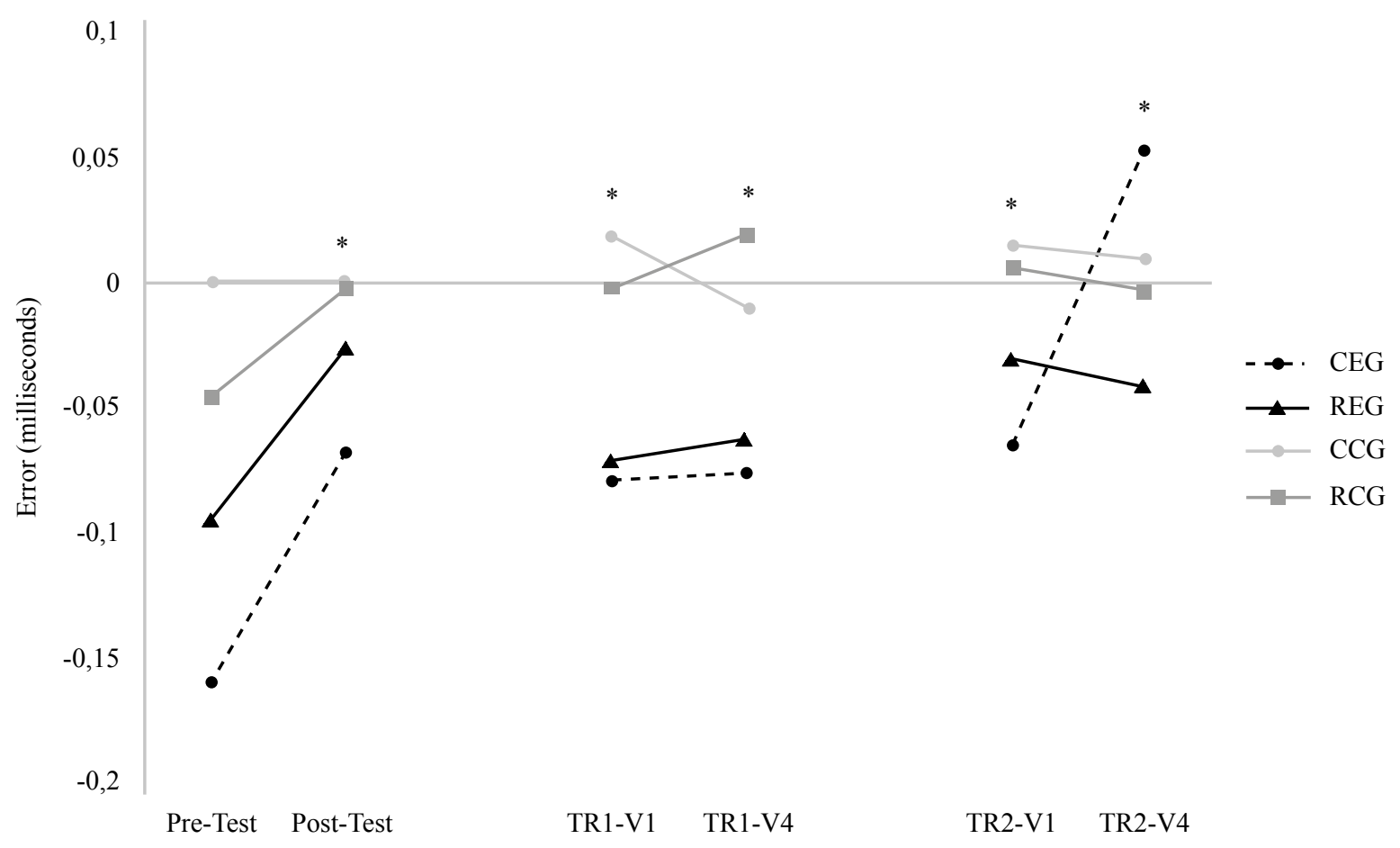


Finally, for variable error the ANOVA two way also revealed effects only for groups considering V1 transfer test $(\mathrm{F}(3,35)=6.93, \mathrm{p}=0.001)$, however post-hoc showed no differences between experimental groups $(\mathrm{p}=0.71)$ and between control groups $(p=0.95)$. The statistical differences were between CCG and CEG $(p=0.03)$ and between RCG and REG $(\mathrm{p}=0.009)$.
For V4 analyses, the ANOVA two way showed in Groups $x$ Moments condition $((F(3,35)=2.05, p=0.04)$; in this sense, Tukey TSD test showed that this differences was due the interaction between CCG and CEG $(p=0.04)$.

In sum, these results in relation to variable error evidence that people with stroke showed more variability in their motor responses than healthy people along of all experimental period.

Figure 3= Mean of the variable error along blocks of trials for all groups. Legend: CEG - Constant Experimental Group, REG - Random Experimental Group, CCG - Constant Control Group, RCG - Random Control Group, TR1 - Immediate Transfer Test, TR2 - Long Term Transfer Test, V1 - Speed at $1 \mathrm{mph}, \mathrm{V} 4$ - Speed at $4 \mathrm{mph},{ }^{*}$ - Significant difference between REG and RCG, $\uparrow$ - Significant difference between CEG and CCG.

\section{Variable Error}

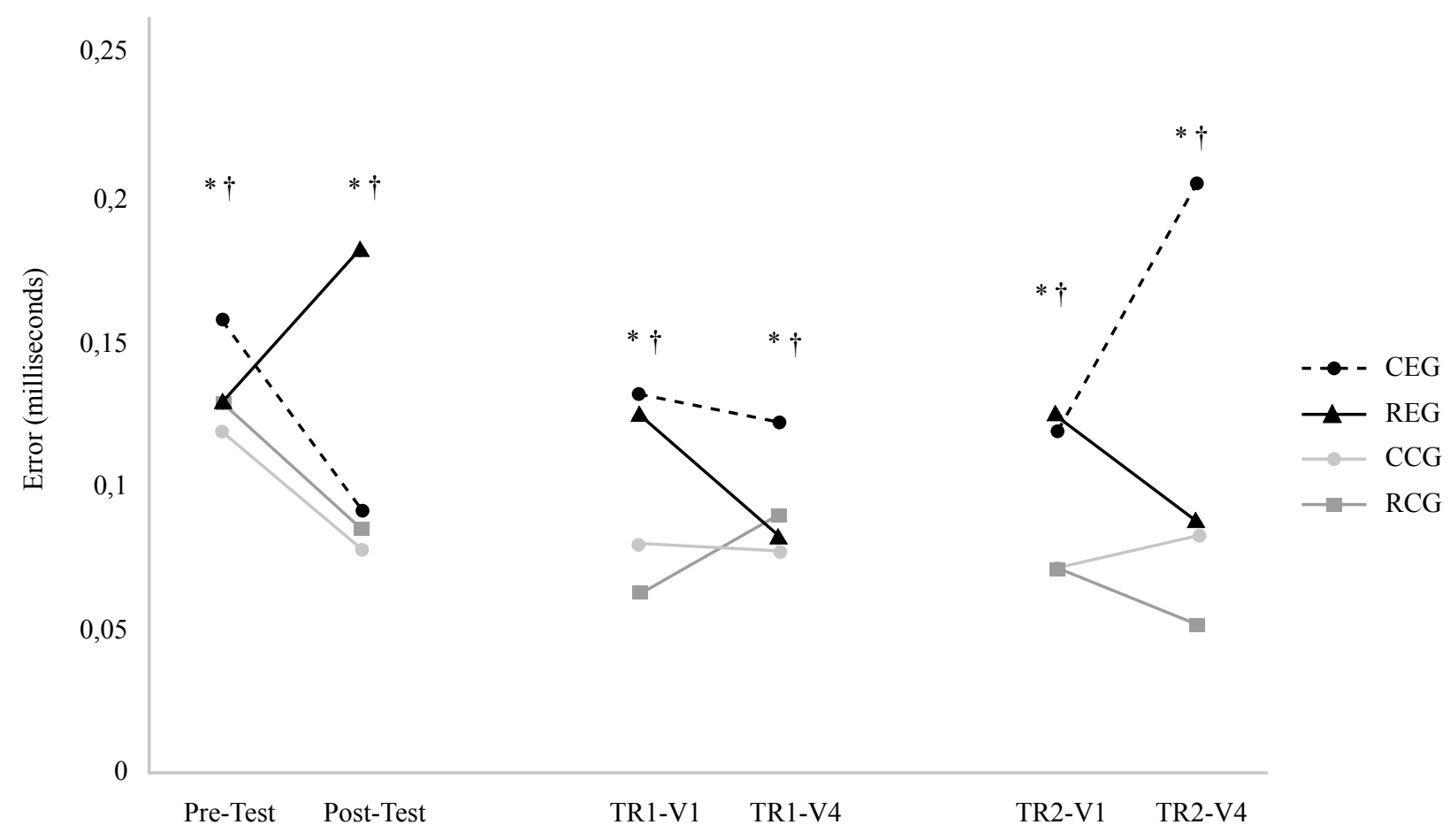

\section{Discussion}

The aim of this study was to investigate the effects of practice schedule on motor learning of a task with temporal synchronization demand in post-stroke patients. Our findings revealed that post stroke people were able to improve their performance and adapt it in transfer tests (short term and long term). Yet, the results showed that post stroke subjects were more variable than control healthy subjects. The participants initiated the acquisition phase with late motor responses and after practice they were more precise or even anticipated, regardless the group. Finally, the practice condition (constant or random) did not influence in any parameter of motor learning for all participants.

Therefore, our findings corroborated partially with the previous hypothesis, given that we have predicted that: (a) post-stroke patients would have the skill of improving their performance and adapt it to variable conditions and, (b) random practice would promote better motor learning than constant practice in both groups, healthy and stroke people $\mathrm{e}^{5,30}$.
The first hypothesis was confirmed since all stroke groups increased the accuracy (absolute error) in the acquisition phase, and the acquired performance levels were kept during the tests (transfer). It allowed us to infer that motor learning has occurred in stroke patients. Besides, practice can decrease error performance for stroke patients because the error decreased from the first block to the others. These results have been observed in other studies ${ }^{28,31-35}$. However, these studies did not use a transfer test to infer the occurrence of motor learning.

Yet, our study also advances for assessing motor learning in transfer test in a long term condition. This condition has been considered as the most appropriated design to infer the occurrence of motor learning process, strongly related to motor memory consolidation ${ }^{1}$.

As expected, even though the stroke affects the performance in coincident timing tasks, with practice they could improve the performance. Given the higher perceptual demand of our task, this performance improvement may be attributed to a better condition of the temporal synchronization, and 
consequently a better anticipation skill. This finding is showed by the constant error results, showing the direction of the error. All participants (stroke and healthy people) showed a tendency of anticipating their motor responses along of practice. Thus, we attribute more importance to perceptual skills involved on the task to explain the equality between stroke and healthy people, than a lower motor demand involved in a press bottom action $22,36,37$.

Our results are different to the other ${ }^{31}$ mainly because the stroke patients could adapt their performance according to the changes on the transfer test (speed change of the stimulus), and they were able to maintain their improved behavior after a short and long transfer test. As far as we know, there are no studies that investigated motor learning in stroke patients including transfer test. In complementary analyses, we still used two different moments for transfer test, to ensure a broad view about the adaptation skills acquired during practice even after a deprived practice period. This strategy allow us to understand about the consolidation and the flexibility of the motor memory acquired during practice ${ }^{1}$.

On the other hand, the second hypothesis was not confirmed given that there was no difference between constant and random practice schedules on motor learning. Thus, these results show that the practice condition did not influence motor learning of a synchronization task for stroke subjects.

Our findings are different from Hanlon ${ }^{17}$ that affirmed that even though random practice was not effective in promoting changes in performance during the acquisition phase, it was more effective in the retention tests. The literature however relies on the superiority of varied practice through the transfer test and not on retention test ${ }^{38}$.

It has been predicted that random variable practice would lead to better motor learning than constant practice in healthy subjects, in spite of some controversial results ${ }^{4}$. According to Shea and Wulf ${ }^{5}$, learning a new skill may require the learning of both the generalized motor program (GMP) and the appropriate parameterization of the movement. The present results reinforce their assumption that if a new GMP should be learned early in practice, parameter variability may impair (but not prevent) the learning of a stable GMP. Moreover, Corrêa and collaborators ${ }^{39}$, suggest that adapting to a new task or situation may depend on the redundancy achieved by the system during the acquisition phase rather than on the generalization of rules capacity acquired by randomly varied practice. However, those assumptions did not support our results, which remain uncertain the influence of practice structure in stroke motor learning process.

In fact, the effect of contextual interference on motor learning of post-stroke subjects still needs more investigation. It is still necessary to: 1 - investigate contextual interference on post-stroke individuals with more complex tasks, which provide the possibility to generalize for Activities of Daily Living (ADLs), 2 - investigate whether the contextual interference influences motor learning on different effector limb conditions, (ie. paretic or not paretic limb), 3 - investigate contextual interference on different levels of injury (cognitive, motor or perceptual impairments).
Finally, our findings also confirm that apparently post-stroke subjects are more variables than control persons. In fact, this variability has been reported in some studies in the literature ${ }^{17,33,40-42}$. This higher variability of responses is demonstrated by a larger confidence interval when compared to healthy people ${ }^{17,33,40-42}$. To note, variability not always is interpreted as a worse motor condition $^{43}$. In postural control, for example, the variability reflects a more adaptable system ${ }^{44}$. Variability can be associated to a transitory condition during the transition of the motor learning stages, which reflects motor improvement ${ }^{45,46}$. Nevertheless, in the accurate tasks, the variability tends to decrease during the acquisition process, and in this case, can be interpreted as an error measure.

Therefore, measures that reflect variability of motor responses can offer a more complete indication about the motor system and how the performance is changing along of acquisition phase; this measure is strongly suggested in the next studies about motor learning and stroke people.

One possible limitation of this study could be the hand used by the control participants in relation to the dominance of the hand used by stroke participants. In this study, the participants performed the task with the non-paretic upper limb; therefore, the results were mainly based on memory consolidation processes and related to the motor impairment deficits itself. However, during the ADLs performance of stroke patients, both motor and cognitive impairment impact the performance. It may need to be reconsidered in future study designs to assess cognitive / memory process and its impact on the motor performance and learning. In fact, this situation may have influenced the results of this study.

However, our findings showed important results regarding the motor learning in stroke people. As our objective was to determine the impact of the practice structure in the motor learning without or less motor control deficits present in paretic limb, we proposed to solve this issue incorporating the performance of the task with the nonparetic limb.

The difference between stroke and health subjects found on learning a temporal synchronization may be derived more exclusively from output deficits. Given that, stroke subjects when perform and learn this task with the nonparetic limb, seem to have same conditions of motor learning when compared to the control group. However, this conception needs to be considered exclusively for mild to moderate impairment patients; in special in terms of cognitive and motor disabilities, based on the sample characterization according to Fugl Meyer and Mini Mental State Exam. Therefore, the participants of this study do not represent several cognitive and motor impairment patients, which may show different conditions of motor performance and learning.

In conclusion, considering: 1 - the sample characteristics, 2 - the specificity of coincident timing task that associates low effector demand to high cognitive demand, and 3 - the utilization of the less impaired upper limb that even though neurological mechanisms are impaired; motor learning is preserved after stroke. Besides, stroke does not affect the capacity to adapt the motor performance as well as it maintenance in short and longterm tests. However, there were no effects of practice schedule on motor learning in post-stroke patients. 


\section{Conclusion}

Motor learning is preserved after stroke and the capacity to adapt the motor performance as well as it maintenance in short and long-term tests is intact when the task is performed by non-paretic limb. There were no effects of practice schedule on motor learning in post-stroke subjects.

\section{References}

1. Kantak SS, Winstein CJ. Learning-performance distinction and memory processes for motor skills: A focused review and perspective. Behav Brain Res [Internet]. 2012 Mar;228(1):219-31. Available from: http://linkinghub.elsevier.com/retrieve/pii/ S0166432811008278

2. Krakauer JW. Motor learning: its relevance to stroke recovery and neurorehabilitation. Curr Opin Neurol. 2006;19(1):84-90.

3. Porter JM, Magill RA. Systematically increasing contextual interference is beneficial for learning sport skills. J Sports Sci. 2010 Oct;28(12):1277-85.

4. Van Rossum JHA. Schmidt's schema theory: the empirical base of the variability of practice hypothesis: A critical analysis. Hum Mov Sci. 1990;9(3):387-435.

5. Shea CH, Wulf G. Schema theory: a critical appraisal and reevaluation. J Mot Behav. 2005 Mar;37(2):85-101.

6. Lin $\mathrm{C}-\mathrm{H}$, Winstein $\mathrm{C}$, Fisher B, Wu A. Neural Correlates of the Contextual Interference Effect in Motor Learning: A Transcranial Magnetic Stimulation Investigation. J Mot Behav [Internet]. 2010 Jul 1;42(4):223-32. Available from: http://www.informaworld. com/openurl?genre $=$ article $\&$ doi $=10.1080 / 00222895.2010 .492$ 720\&magic $=$ crossref $\% 7 C \% 7 C D 404 A 21 \mathrm{C} 5 \mathrm{BB} 053405 \mathrm{~B} 1 \mathrm{~A} 640$ AFFD44AE3

7. Schweighofer N, Lee J-Y, Goh H-T, Choi Y, Kim SS, Stewart $\mathrm{JC}$, et al. Mechanisms of the contextual interference effect in individuals poststroke. J Neurophysiol [Internet]. 2011 Nov 1;106(5):2632-41. Available from: http://jn.physiology.org/cgi/ doi/10.1152/jn.00399.2011

8. Kantak SS, Sullivan KJ, Fisher BE, Knowlton BJ, Winstein CJ. Transfer of motor learning engages specific neural substrates during motor memory consolidation dependent on the practice structure. J Mot Behav. 2011 Jan;43(6):499-507.

9. Krakauer JW. The applicability of motor learning to neurorehabilitation. In: Oxford Textbook of Neurorehabilitation [Internet]. Oxford University Press; 2015. p. 55-64. Available from: http://www.oxfordmedicine.com/view/10.1093/ med/9780199673711.001.0001/med-9780199673711-chapter-7

10. Winstein CJ, Merians AS, Sullivan KJ. Motor learning after unilateral brain damage. Vol. 37, Neuropsychologia. 1999. p. 975-87.

11. Kal E, Winters M, Van Der Kamp J, Houdijk H, Groet E, Van Bennekom C, et al. Is Implicit Motor Learning Preserved after Stroke? A Systematic Review with Meta- Analysis. 2016;1-23. Available from: http://dx.doi.org/10.1371/journal.pone.0166376

12. Beis J, Paysant J, Bret D, Chapelain L Le, Andre J. Asomatognosia in Right Hemisphere Stroke. Stroke. 2007;20(3):163-9.
13. Lee G, An S, Lee Y, Lee D, Park D. Predictive factors of hypertonia in the upper extremity of chronic stroke survivors. J Phys Ther Sci. 2015;27(8):2545-9.

14. Miralbell J, Soriano JJ, López-Cancio E, Arenillas JF, Dorado L, Barrios M, et al. [Vascular risk factors and cognitive performance in patients 50 to 65 years-old]. Neurologia. 2010 Sep;25(7):422-9.

15. Censor N, Dimyan MA, Cohen LG. Modification of existing human motor memories is enabled by primary cortical processing during memory reactivation. Curr Biol. 2010;20(17):1545-9.

16. Boyd L a., Edwards JD, Siengsukon CS, Vidoni ED, Wessel BD, Linsdell $\mathrm{M}$ a. Motor sequence chunking is impaired by basal ganglia stroke. Neurobiol Learn Mem [Internet]. 2009;92(1):35-44. Available from: http://dx.doi.org/10.1016/j.nlm.2009.02.009

17. Hanlon RE. Motor Learning Following Unilateral Stroke. Arch Phys Med Rehabil. 1996;77:811-5.

18. Cauraugh JH, Kim SB. Stroke motor recovery: active neuromuscular stimulation and repetitive practice schedules. J Neurol Neurosurg Psychiatry. 2003;74(11):1562-6.

19. Kantak SS, Sullivan KJ, Fisher BE, Knowlton BJ, Winstein CJ. Neural substrates of motor memory consolidation depend on practice structure. Nat Neurosci [Internet]. 2010 Aug 11;13(8):923-5. Available from: http://www.nature.com/doifinder/10.1038/nn.2596

20. Winstein C, Lewthwaite R, Blanton SR, Wolf LB, Wishart L. Infusing Motor Learning Research Into Neurorehabilitation Practice: A Historical Perspective With Case Exemplar From the Accelerated Skill Acquisition Program. J Neurol Phys Ther. 2014 Jul;38(3):190-200.

21. Schmidt RA, Lee TD. Motor Control and Learning: A Behavioral Emphasis. 5th ed. Champaign: Human Kinetics; 2011.

22. Billing J. An Overview of Task Complexity. Mot Ski Theory into Pract. 1980;4(1):18-23.

23. Wade MG, Newell KM, Hoover JH. Coincident timing behavior of young mentally retarded workers under varying conditions of target velocity and exposure. Am J Ment Defic. 1982 May;86(6):643-9.

24. POULTON EC. On prediction in skilled movements. Psychol Bull. 1957 Nov;54(6):467-78.

25. Corrêa UC, Massigli M, Barros JA de C, Gonçalves LA, de Oliveira JA, Tani G. Constant-random practice and the adaptive process in motor learning with varying amounts of constant practice. Percept Mot Skills. 2010;110(2):442-52.

26. Corrêa UC, Tani G. Aparelho de timing coincidente em tarefas complexas. Rev da Propr Ind. 2004;1763:178.

27. Torriani-Pasin C, Bonuzzi GM, Soares MA, Antunes GL, Palma GC, Monteiro CB, et al. Performance of Down syndrome subjects during a coincident timing task. Int Arch Med [Internet]. 2013;6(1):15. Available from: http://www.pubmedcentral.nih. gov/articlerender.fcgi? artid=3661389\&tool=pmcentrez\&rende rtype $=$ abstract

28. Boyd LA, Winstein CJ. Cerebellar stroke impairs temporal but not spatial accuracy during implicit motor learning. Neurorehabil Neural Repair. 2004;18(3):134-43.

29. Perez CR, Meira CM, Tani G. Does the contextual interference effect last over extended transfer trials? Percept Mot Skills. 2005 Feb;100(1):58-60.

30. Schmidt RA. A schema theory of discrete motor skill learning. Psychol Rev. 1975;82(4):225-59. 
31. Meehan SK, Randhawa B, Wessel B, Boyd LA. Implicit sequencespecific motor learning after subcortical stroke is associated with increased prefrontal brain activations: an fMRI study. Hum Brain Mapp. 2011 Feb;32(2):290-303.

32. Platz T, Denzler P, Kaden B, Mauritz KH. Motor learning after recovery from hemiparesis. Neuropsychologia. 1994;32(10):1209-23.

33. Vidoni ED, Boyd LA. Preserved motor learning after stroke is related to the degree of proprioceptive deficit. Behav Brain Funct [Internet]. 2009;5(1):36. Available from: http://behavioralandbrainfunctions.biomedcentral.com/articles/10.1186/1744-9081-5-36

34. Pohl P, McDowd J, Filion D, Richards L, Stiers W. Implicit learning of a motor skill after mild and moderate stroke. Clin Rehabil. 2006 Mar;20(3):246-53.

35. Winstein C. Motor learning after unilateral brain damage. Neuropsychologia [Internet]. 1999 Jul 1;37(8):975-87. Available from: http://www.ncbi.nlm.nih.gov/pubmed/10426521

36. Tomassini V, Jbabdi S, Kincses ZT, Bosnell R, Douaud G, Pozzilli $\mathrm{C}$, et al. Structural and functional bases for individual differences in motor learning. Hum Brain Mapp. 2011 Mar;32(3):494-508.

37. Badets A, Blandin Y. Feedback Schedules for Motor-Skill Learning: The Similarities and Differences between Physical and Observational Practice. J Mot Behav. 2010 Jul;42(4):257-68.

38. Edwards WH. Motor learning and control : from theory to practice. Wadsworth Cengage Learning; 2011. 519 p.

39. Corrêa UC, Benda RN, Meira Júnior CM, Tani G. Practice schedule and adaptive process in the acquisition of a manual force control task. J Hum Mov Stud. 2003;44(2):121-38.

40. Bonuzzi GMG, Freitas TB, Corrêa UC, Freudenheim AM, Pompeu JE, Torriani-Pasin C. Learning of a postural control task by elderly post-stroke patients. Motricidade [Internet]. 2016;12(1):141. Available from: http://revistas.rcaap.pt/ motricidade/article/view/7004

41. Boyd LA, Quaney BM, Pohl PS, Winstein CJ. Learning Implicitly: Effects of Task and Severity After Stroke. Neurorehabil Neural Repair [Internet]. 2007 Mar 16;21(5):444-54. Available from: http://nnr.sagepub.com/cgi/doi/10.1177/1545968307300438
42. Boyd LA, Winstein CJ. Implicit motor-sequence learning in humans following unilateral stroke: the impact of practice and explicit knowledge. Neurosci Lett [Internet]. 2001 Jan;298(1):65-9. Available from: http://linkinghub.elsevier.com/retrieve/pii/ S0304394000017341

43. Latash ML, Scholz JP, Schöner G. Toward a new theory of motor synergies. Motor Control [Internet]. 2007 Jul;11(3):276-308. Available from: http://www.ncbi.nlm.nih.gov/pubmed/17715460

44. Latash ML, Nicholas JJ. Motor control research in rehabilitation medicine. Disabil Rehabil [Internet]. 1996;18(6):293-9. Available from: http://search.ebscohost.com/login.aspx?direct= true \&AuthType $=\mathrm{ip}$, shib\&db=jlh\&AN=1998033753\&site $=$ eho st-live \&scope $=$ site

45. Tani G, Correa UC, Basso L, Benda RN, Ugrinowitsch H, Choshi $\mathrm{K}$. An adaptive process model of motor learning: insights for the teaching of motor skills. Nonlinear Dynamics Psychol Life Sci [Internet]. 2014;18(1):47-65. Available from: http://www.ncbi. nlm.nih.gov/pubmed/24314130

46. Tani G. Processo adaptativo em aprendizagem motora: o papel da variabilidade. Rev Paul Educ física. 2000;(3):55-61.

\section{Corresponding author}

Giordano Marcio Gatinho Bonuzzi

Universidade de São Paulo Escola de Educação Física e Esporte. Professor Mello de Morais avenue, São Paulo, SP, Brasil. Email: giordanomgb@gmail.com

Orcid: http://orcid.org/0000-0002-3751-2857

Manuscript received on September 30, 2017

Manuscript accepted on February 21, 2018

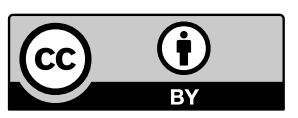

Motriz. The Journal of Physical Education. UNESP. Rio Claro, SP, Brazil - eISSN: 1980-6574 - under a license Creative Commons - Version 4.0 